\title{
The Driving Forces of Facebook Social Commerce
} Ahmad Samed Al-Adwan ${ }^{1}$ and Husam Kokash ${ }^{2}$

\author{
${ }^{1}$ Al Ahliyya Amman University, Business School, Department of Information Systems, Amman, Jordan, \\ a.adwan@ammanu.edu.jo \\ 2 Al Ahliyya Amman University, Business School, Department of Marketing, Amman, Jordan, \\ h.kokash@ammanu.edu.jo
}

Received 21 May 2018; received in revised form 20 July 2018; accepted 27 July 2018

\begin{abstract}
Trust is viewed as a crucial factor in social commerce due to the prominent role and significant amount of peer-generated contents. The current study aims to investigate the relationship between trust in social commerce and customers' purchase intentions by providing a mechanism to describe this relationship. Thus, a proposed model is developed based on three concepts: social presence, social commerce information seeking and familiarity with the platform. The model explains the mechanisms through which social commerce information seeking, familiarity, social presence and trust influence customers' intentions to purchase from social commerce platforms. For the purpose of this study, a survey is designed and distributed to Facebook users. The findings demonstrate that trust in a social networking site has positive influence on purchase intentions. Moreover, trust encourages information seeking, which in turn improves purchase intentions. Furthermore, both social presence and familiarity are found to enhance trust and purchase intentions. According to the findings, several managerial and theoretical implications are highlighted. Particularly, as the first study to investigate the adoption of social commerce among Jordanian customers, this study offers valuable insights and implications for Jordanian firms' managers and marketers who are targeting direct sales on social networking platforms.
\end{abstract}

Keywords: Social commerce, Social media, Trust, Information seeking, Social presence, Familiarity, Social networking sites (SNSs), Social commerce platforms, Facebook 


\section{Introduction}

A major difference that characterises the online and offline shopping is the low level of human and social presence [6]. This difference is noted to act as a barrier to e-commerce development. Frequently, the low presence is considered as a key limitation of e-commerce. According to [71], the absence of social and human presence in ecommerce is linked with increased risk, reduced social cues, and acts as a barrier to a conducive business environment. However, the integration of Web 2.0 technologies into e-commerce sites has greatly improved social presence. As a result, the concept of social commerce has emerged [93]. Web 2.0 technologies have significantly participated in making social interactions and social presence among customers feasible. Web 2.0 technologies facilitate the collection of significant information through various core features such as content sharing and usergenerated contents [50]. The impact of such features can be demonstrated in both customers' social interaction and business outcomes. Web 2.0 technologies considerably impact the reliability of a business transactions and its reputation. In addition, these technologies help businesses to strengthen their relationships with customers and improve the effectiveness of developing a new brand or product. In contrast, customers can effectively benefit from web 2.0 technologies. Specifically, customers' preferences, decisions and perceptions are not only steered by information available on e-commerce websites, but are also impacted by content generated by peers on social networks.

Regarding innovations in information and communication technology, social commerce is the latest development [65]. Though social commerce has evolved just recently, its practical development is rapid [10]. The rapid growth is associated with the rapid growth and popularity of social media networks which have significantly led to the growth of social communities and facilitated peer interaction [67]. As a result, many businesses today have been presented with new opportunity for supporting their businesses using social networks in what is referred to as social commerce. Chen and Shen [17] noted that online transactions are promoted by social commerce made possible by social networking sites which allow people to share, communicated, recommend, and even provide product ratings based on their experiences.

As a result, many service providers (i.e. airlines, insurance) and retailers (e.g., Samsung) have succeeded in using social commerce effectively to improve the performance of their businesses. Nevertheless, Liang and Turban [67] argue that some organisations have been unsuccessful in their strategies regarding social commerce and there have been several issues in respect of privacy, trust and security in exchanging information. Trust is recognised as key factor preventing customers from making online purchases. Nonetheless, in social commerce, social networking sites (SNSs) provide notifications about products and customers in turn may make purchases. Therefore, trust in SNSs and the embedded content given by peers can significantly enhance customers' intentions to purchase from online sellers. Trust in social commerce enables companies to boost purchase intentions and word-of-mouth [59]. However, Hajli et al. [41] assert that there is lack of research in the context of social commerce that investigates the role of trust in SNSs on influencing customers' intentions to purchase from online vendors, and how the effects of trust (if there is any) can be transferred to purchase intention. Thus, this study bridges this gap by aiming to explain the relationship between trust and customers' purchase intention from online-vendors via an social networking site (SNS). Moreover, this study seeks to build a mechanism that describes how trust in SNSs influence purchase intention.

A report conducted by the Arab Advisor Group [8] points out that the overall number e-commerce users in Jordan is 514,000 , which constitutes $8.2 \%$ of the total population. Additionally, the report estimates the total spending on ecommerce services in Jordan (taken in 2011) at US\$ 370 million. The report reveals that $24.4 \%$ of the Jordanian Internet users use e-commerce to purchase services and products and pay bills online, compared to $15.4 \%$ in 2010 . The report also highlights the remarkable rise from US\$192 million spent in 2010. Such figures show that Jordan can be viewed as an appropriate marketplace for e-commerce activities among the developing countries in the Arab and Middle East regions. Thus, several studies have investigated e-commerce adoption in Jordan [4], [44], [107]. However, empirical research on social commerce adoption, particularly the adoption of social commerce through SNS platforms, among Jordanian customers has not yet been investigated. Accordingly, this research is the first one to study behavioural intentions of Jordanian customers to adopt social commerce through a SNS platform such as Facebook. This study aims at answering the following research question: How trust in a SNS platform influence customers' behavioural intentions to purchase from e-sellers through Facebook social commerce in Jordan?. Specifically, the main objective of study is to explore the interactions and relationships among trust in a SNS platform, social presence, information seeking, familiarity with a SNS platform and their effects on customers' behavioural intention to purchase from e-sellers through Facebook social commerce. Facebook was selected for the purpose of this study because it is one of the most popular and well-known SNS worldwide and an appropriate platform for social commerce activities. Consequently, by answering this question, this study is expected to offer valuable insights and implications for Jordanian firms' managers and marketers who are targeting direct sales on social networking platforms. 


\section{Social Commerce}

Recently, social media technologies have gained a lot of popularity among global citizens. As a result, Lal [65] notes that many businesses today have a lot of opportunities and tools for enhancing their online visibility. There is not an agreed definition of social commerce as many authors provide different definitions. Lu et al. [71] refer social commerce to the use of social media platforms to deliver the various transactions and activities of e-commerce. On the other hand, Hettiarachchi et al. [49] define social commerce as an Internet-based social media that facilitates the active participation of people in selling and marketing of services and products through online communities and marketplaces. Another description of social commerce is provided by [67] as a category of e-commerce that utilizes Web 2.0 social media technologies for facilitating online interaction and contributions of online users in acquiring products and services. Busalim and Hussin [12] also referred to social commerce as a subset of e-commerce but facilitated by offline and online social environments. Another definition of social commerce was also provided by [42] who described it as a development of e-commerce that makes use of social media technologies which allows the facilitation of buyer interaction that leads to the creation of active content such as reviews and recommendations that guides other buyers in making decisions that inform their purchasing of products and/or services.

Some of the popular e-commerce websites such as Amazon and eBay have integrated their applications with social media content and applications that promote communication among buyers when they make a purchase. Liang and Turban [67] state that social commerce can be considered as a concept that mixes social and economic features and is characterised by community interactions facilitated by social technologies and commercial activities. Yadav et al. [106] also defined social commerce as a subset of e-commerce but one that makes use of social networking technologies to support e-commerce activities and transactions.

In general, shopping is taken as a social activity. Lu et al. [71] noted that social relationships impact the decision of a person to make a purchase. E-commerce differs from traditional commerce in that e-commerce sites do not have the warmth and sociability that comes with face-to-face shopping experiences associated with traditional commerce [91]. Additionally, e-commerce differs from traditional commerce as it has lower cognitive load, and is considered anonymous, impersonal, and computerised. Furthermore, Mesquita [76] has argued that e-commerce websites with main features that support only the essential transactional aspects of online shopping (such as credit card guarantees) are considered information-lean. This is particularly due to the emphasis that e-commerce sites place on one-way interaction between the system and users and on increasing efficiency [50].

The initiation and management of social interactions in the past between sellers and buyers was not only costly but also unfeasible [18]. However, the advent of social technologies brought the social aspect to online purchasing and therefore brought more social experience. Additionally, social technologies have also increased the ability of businesses to manage and initiate social interactions with buyers in a way that is not only inexpensive but very manageable. While the focus of e-business is on business objectives, it has been noted that social commerce is primarily aimed at social goals such as information sharing and networking with its secondary objective being stimulating consumer purchases [102]. With social commerce, buyer gain better understanding, knowledge, and more information that informs their online purchase decisions.

Huang and Benyoucef [50] state that the literature has suggested two main categories of social commerce. The first category is fundamentally based on e-commerce websites equipped with Web 2.0 technologies and tools to improve interaction among customers and enhance their content generation. In this category, customers are limited in terms of providing comments on other customers' reviews. Furthermore, customers are prevented from interacting further with these reviews as they cannot establish communities, send private messages or add other customers. The second category, which is the emphasis of the current study, is inherently based on a Web 2.0 platform that integrates e-commerce characteristics, such as the page of any commercial company or brand on Facebook. Such social commerce platforms (e.g., Facebook, Instagram) offer a variety of channels for customer to customer (C2C) and business to customer (B2C) connections, and allow various forms of cooperation between online venders and customers in terms of creating contents. Online-sellers are capable to co-create or create their own pages with the assistance of customers; they can post news, promotions, upload videos and pictures on their pages and interact with their customers through several methods. Customers also become more empowered by being able to react, share, rate and comment on online-vendors' products/services and communicate with other customers.

\section{Trust}

According to [71], trust is a complex and multidimensional term and for this reason, different scholars have defined trust differently. $\mathrm{Ng}$ [80] defined trust as a party's readiness to submit to the vulnerability created by the actions of another party with the expectation that the other party will act according to the trustor regardless of this party's capacity to monitor or exercise control over the other party. Four broad forms of trust were proposed by Mcknight et al. [75] including trusting beliefs, institution-based trust, disposition to trust, and trusting intentions. These conceptualizations were also adopted by [48]. However, these trust beliefs are further conceptualised into three categories which are integrity, ability, and benevolence. Trust was also defined by Ou et al. [81] as the buyer's 
degree of perception of the seller's integrity, ability, and benevolence. The ability of the seller refers to the products characteristics, competence, and seller's skills. On the other hand, integrity is the capability of the seller to follow certain buyer acceptable principles and disciplines. Benevolence also refers to the general tendency of the seller to help and support the buyer. In line with [96], this study refers to trust the trusting beliefs that one can rely upon a promise made by another and that the other, in unforeseen circumstances, will act toward oneself with goodwill and in a benign fashion (p.137).

In commercial transactions, trust plays a major role and for this reason a lot of researchers in both social commerce and e-commerce have studied it [43]. Trust forms the foundation of long-term relationships in online contexts [65] [101]. This is because, online transactions are associated with a certain level of uncertainty and risk not found in traditional commerce. Therefore, when trust is high, uncertainty is reduced significantly and thus stimulating more online transactions among buyers. Lu et al. [71] noted that trust acts decreases the social complexity associated with the lack of the governing systems for online transactions. Trust plays an effective role in controlling opportunistic behaviour that may arise due to lack of regulations in online transactions. For this reason, trust is recognised an important aspect in e-commerce as it promotes successful e-commerce and therefore social commerce.

Online shopping has been subjected to many transaction-related issues that affect customers' decision to make an online purchase [60]. Trust is viewed as being an essential factor in both e-commerce and social commerce contexts since face-to-face transactions are the main method of communication between buyers and sellers who are geographically dispersed. The absence of face-to-face interaction might lead to distrust in online transactions, and also the scarcity of knowledge about online sellers can increase the impact of risk in online shopping [56]. Simultaneously, buyers lack direct experience with regard to products as they cannot feel or touch them. Moreover, payment guarantees are may be absent during online transactions [9]. Furthermore, it has been reported that several issues related to online purchase, such as incorrect products being received, product quality, and no, late or wrong delivery, inhibits buyers from purchasing online [97]. Such circumstances result in high levels of risk and uncertainty [25].

An intensive investigation of the concept of trust in e-commerce has been provided by authors such as [20], [22], [55], [77]. These researchers investigated how trust influences the intentions of online buyers to make a purchase. Other previous studies such as those conducted by [13], [16], [101] identified the antecedents of trust and developed mechanisms for building trust. However, the majority of these studies focussed on how functionality (usefulness, ease of use and usability) and institutional structures (such as assurance, normality and quality) affect e-commerce and paid little attention on the social aspects [71] and exempted social presence created by website interfaces [91] [90]. The interaction between individuals and the surrounding environment forms the basis for developing trust. According to [90], the occurrence of trustworthy interactions between individuals forms the basis for development of trust and therefore social context is important. However, previous literature has largely overlooked the aspect of social context.

For a couple of years, social commerce has rapidly grown. A report conducted by [98], global social commerce market is expected to grow at a compound annual growth rate (CAGR) to reach $34 \%$ by 2021 . The report points out that the increased use of social media advertising is recognised as one of the key growth factors for social commerce. Additionally, the report demonstrates that the constant growth of social media users and the ability of social media to provide various product portfolios are identified as other important factors for social commerce. Despite this growth, trust remains a fundamental element for the success of e-commerce businesses and consequently many such businesses are putting extra effort to develop their trust with buyers. The absence of faceto-face interactions and the massive amount of user -generated contents in social commerce are the reason behind the high uncertainty in social commerce [27]. Despite this claim, Gefen and Straub [30] posit that reduced uncertainty through trust-building and increased tendency towards online commerce arises from an improved experience with exchange parties. The main antecedents of trust and its impacts on intentions to purchase online through social commerce platforms were explored by a study conducted by [60]. Kim and Park [60] found seven factors that are considered as important antecedents of trust in social commerce; these are communication, word-of-mouth, economic feasibility, referrals, information quality, size, and transaction safety. Additionally, trust building in ecommerce websites is also enabled by customer reviews and experiences that are shared in online communities and forums. The literature has provided a tangible illustration that the existence of trust in online contexts results in trustrelated outcomes. For example, Gefen and Pavlou [32] explain that trust played an essential role in influencing the intentions of buyers when it came to buying products or services online. Additionally, Indiani et al. [52] state that trust affects the decision of buyers to transaction online while Fang et al. [26] showed that trust influences the repurchasing intentions of online buyers.

\section{Research Model and Hypothesis Development}

In order to achieve the aims of the current study, a proposed research model has been developed (see figure 1). The proposed model aims at explaining the relationship between trust and customers' purchase intention from onlinevendors on a SNS. Essentially, the proposed model is built on 3 main constructs: 1) information seeking which refers to information acquisition from the various information acquisition channels in a SNS, 2) social presence which refers to the sense of sociability and human warmth within a SNS and 3) familiarity which refers to the understanding of a 
SNS's procedures and features. Information exchange channels have been remarkably developed in light of the advent of SNSs. Hajli and Sims [37] point out customers in social commerce are able to seek information about products though several channels (i.e. forums, reviews, comments, ratings, recommendations, communities). However, it has been argued that familiarity with SNSs increases users' dependency on peer-generated contents which in turn may positively influence their purchase intention [100]. Furthermore, both of social presence and information seeking could motivate customers' purchase intention. The research model its relationships are shown in Figure 1 below.

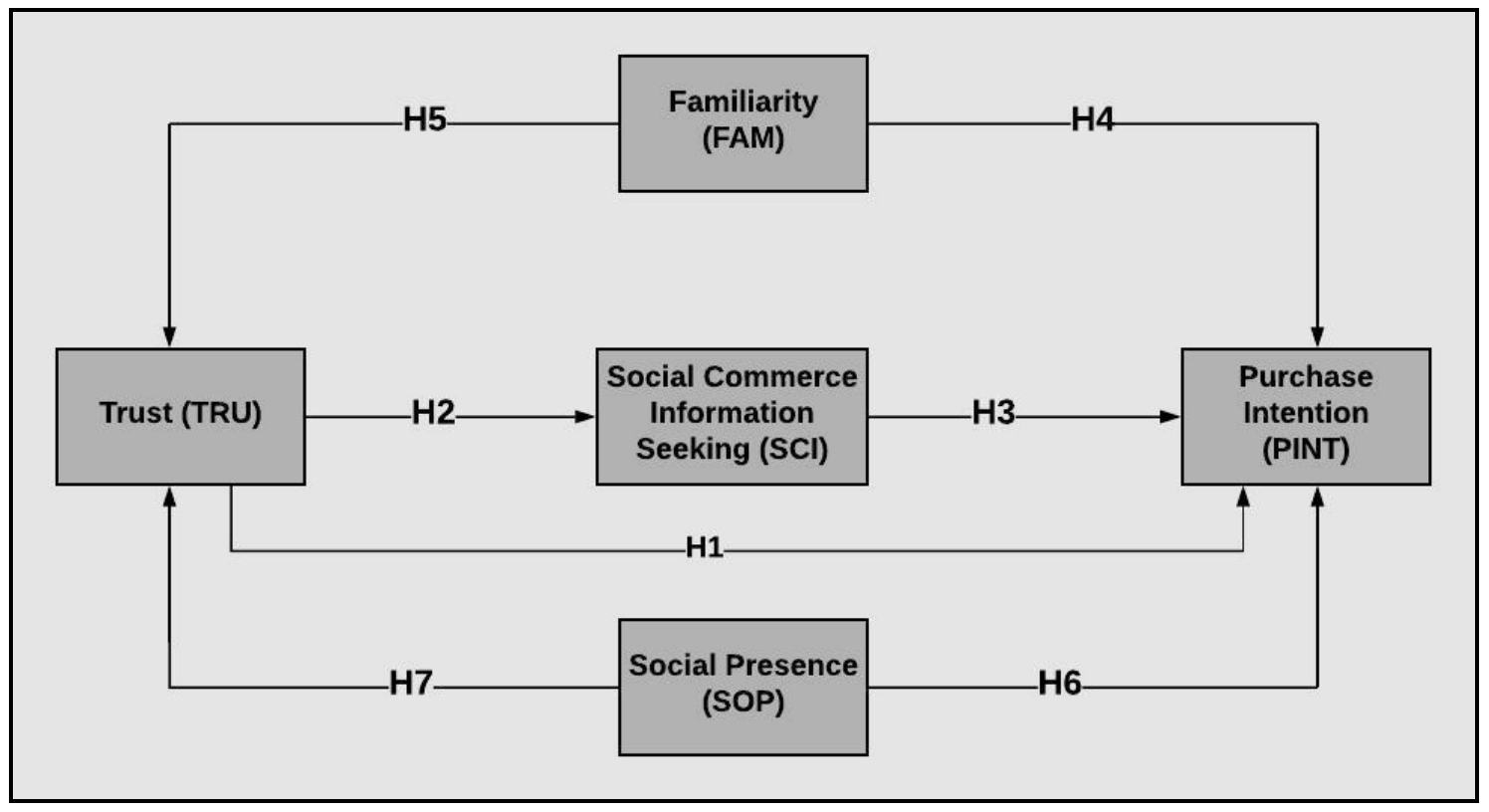

Figure 1: The research model

\subsection{The Influences of Trust in a SNS on Purchase Intention}

The intention to purchase refers to the intention of the customers to buy products or services from online sellers residing on SNSs. Ajzen [2] noted that behaviour can be predicted from behavioural intention. Therefore, the customer purchase behaviour in this study is predicted from the intention of the customer to make a purchase. In online transactions, the absence of face to face interactions between sellers and buyers creates a lot of social complexity and uncertainty that arises from the unpredictable and opportunistic behaviour that the seller may have [71]. Unproved feelings or general beliefs can be regarded as equal to trust. Li et al. [66] also noted that trust for the seller can be obtained when the buyer perceives that the seller has the capacity to provide the customer with the required product or even a product with better quality as arising from online purchases. Therefore, trust can be said to mediate buyer transaction behaviour which subsequently leads to the generation of buyer transaction intentions [54]. The feeling of vulnerability that the customer experiences when making online purchases is decreased by trust which allows the buyer to subjectively control the seller undesirable behaviour. As such, trust can be said to help buyers deal with online vendors by reducing the seller's perceived risk. Hence, buyers are encouraged to engage online vendors by trust and therefor participate in trust-related behaviour such as conducting online purchases and sharing information [60].

This study proposes that trust in a specific SNS can enhance customers' intention to make purchases. Social networking sites, as social commerce platforms, allow customers to effectively communicate with online-sellers and facilitate the value exchange among the different parties. Customers on SNSs encounter recommendations, news/pictures/news, Likes and advertisements related to online-vendors. Nevertheless, the trust in an SNS platform may guide customers' trustworthiness of the contents and the online-sellers' activities. Similar to the classification of trusting beliefs proposed by [74], trusting beliefs in SNSs may include: 1) benevolence, demonstrating the capability of the SNS to accomplish useful actions for users, apart from an egotistic motive of profit; 2) integrity, rooted in the ethical actions of the SNS and fulfilment of promises; 3) predictability, as in the steadiness of the SNSs' actions, allowing users to predict future exchanges; and 4), competence or ability of the SNS to perform a successful exchange or provide recovery if the failure occurs from the online-vendor side. Suh and Han [96] point out that such trusting beliefs encourage customers to rely on the user-generated contents, decrease the uncertainty with respect to exchange outcomes, and extend the relationship duration.

Notwithstanding the above argument, when customers lack trust in an SNS platform, but they trust the online-seller, they are less interested making a purchase with the online-seller through the SNS. Rather, they may select other medium to transact with them. Customers tend to assess the benevolence and credibility of the SNS platform to 
decide whether they are keen to transact with an online-vendor on the platform. Credibility incorporates ability and integrity of the SNS platform in terms of delivering the anticipated outcomes, which sequentially improves intentions to purchase on the platform [56]. Thus, it has been suggested that trust in social commerce websites would significantly encourage users to buy on these websites and spread positive word-of-mouth [62]. Accordingly, this study proposes the following hypothesis:

\section{H1: Purchase intention from online-sellers is positively increased by customers' trust in a SNS platform.}

\subsection{The Influence of Trust in a SNS on Information Seeking}

According to [61], information seeking is defined as a process of sense-making in which a person is forming a personal point of view (p. 361). Individuals are actively seeking meanings that fit with their pre-knowledge and make sense in accordance with their personal presumptions. Griffin et al. [36] point out that the behaviour of information seeking consists of three types: 1) monitoring: individuals act as observers and they attempt to seek signals that can be derived from events or others' behaviour; 2) inquiring: individuals ask others for information; and 3), consulting: individuals consult written materials. Information seeking refers to customers' attempts to obtain information about products/online-vendors from existing resources on SNSs (i.e. ratings, reviews, recommendations) to enhance purchase decisions. Acquiring information optimises customers' knowledge about the various aspects regarding products and aids them throughout the process of purchase decision-making. Teo and Yeong [99] suggest that Information seeking is viewed as a trade-off between the costs of the search process for evaluating the alternatives and the benefits obtained from making enhanced decisions. Technology participates in reducing the search costs and enhancing the quality of decisions by utilising diverse channels of information seeking.

Several constructs characterise social commerce. These are social advertising, reviews and ratings, referrals and recommendations, social shopping, communities and forums, and social media [64]. These platforms are used by businesses to facilitate communication between customers. According to [7], the importance of social technologies emanates from the many opportunities that online vendors have in interacting with their customers. Consumers get more chances to get more knowledge through social interactions and therefore grow their trust in the seller [70]. It has been also noted that through Web 2.0 and social media technologies, social commerce allow consumers to share their views, rate products and services, make referrals, and provide recommendations. Additionally, it has been noted that through social networking sites, buyers reassure each other by sharing information and experiences and therefore increase their confidence in the buyer and thus willingness to buy [45].

Customers are widely using ratings and reviews. The act of accessing others' reviews leads to trigger an emotional feeling that assigns a personal aspect to the decision-making process related to purchasing [39]. Furthermore, reviews provide feedback that can significantly impact brand reputation [104]. Online recommendation systems are frequently used by consumers, and this seems to have a major effect on customers' purchasing decisions. Reviews generate a significant quantity of Information that undoubtedly influences customers' intentions to purchase [24], [38]. According to [71], [84], online comment and rating systems provide valuable insights and accurate information about online-vendors' reputation. Such insights and information participate in building customers' trust in online-vendors. For instance, positive feedback can effectively help customers to develop favourable beliefs towards an onlinevendor.

Recommendation review systems as one of the main forms of electronic word of mouth (e-WOM) can also efficiently increase the perception of others. Gabbriellini and Santini [29] refer e-WOM to ...passing of information from person to person, mediated through any electronic means (p.286). Ahmad and Laroche [1] indicate that social support is perceived by customers as informational and emotional support. E-WOM is viewed as a main source of informational and emotional support, particularly when it is incorporated with social commerce constructs (i.e. reviews, recommendations, ratings, communities and forums). For example, the themes in reviews are perceived by potential customers as helpful and informational support. Chen and Xie [15] point out that e-WOM is more important for purchasing decisions than other marketing techniques (e.g. advertisements). The significant influence of e-WOM is well-established due to its numerous features such solicitation, informed behaviour, valence, timing and intervention before and after purchasing. Therefore, e-WOM is regarded as more trusted and independent due to the absence of online-vendors' intervention and influence. According to Cheng et al. [19], valence of e-WOM has great effects when it comes to the probabilities of purchasing products/services by potential customers. This means that valence of eWOM is indirectly connected to the purchase process which costumers experience when buying a service or product. It basically calculates the accumulative percentage of both positive and negative views that are previously recorded by previous buyers. It is indicated by Chen et al. [18] that the level of customer awareness would be enhanced through the informative role which is played by the exposure to positive WOM (PWOM) or negative WOM (NWOM).

PWOM is triggered when there are social cues that deliver positive signs such as significant number of customers who have purchased or intended to purchase a product or service. In this case, costumers would normally feel confident with regards to the honesty, goodwill and ability of e-sellers to offer good products or services [71]. In this regard, it is worth mentioning that research concerned with marketing illustrates that purchasing behaviours of costumers could greatly be influenced and shaped based on observing and mentoring the actions and reviews of previous purchases conducted by other costumers [18]. As a result, this means that customers would follow and take 
into account the experience of previous customers who have conducted online purchases and indulge in group behaviour phenomenon.

Previous studies suggest that seeking information about products on a platform requires customers' trust in the platform sources. Hertzum et al. [47] demonstrate that users' trust influences their information seeking behaviour in relation to virtual agents, people and documents. They state that Users' willingness to engage with a website is strongly dependent on the extent to which the site succeeds in conveying accountability and trustworthiness (p. 581). Hence, customers are encouraged to follow the involved contents when trust in an SNS is attained [103]. In contrast, lack of trust impedes customers from exchanging or sharing information [104]. It has been argued that when customers have positive trust beliefs toward a platform, they are more willing to rely on the platform [74]. Trusting beliefs play an important role in allowing for other behaviours related to trust such as information exchange. Furthermore, varied levels of risk are involved in forming trust, depending on the product, which force customers to search information from various sources to investigate products and vendors. Yigitcanlar [108] states that one's trust in another is likely to shape the extent to which people will be forthcoming about their lack of knowledge (274). Accordingly, establishing trust in a platform motivates customers to seek information about products through the different sources, such as ratings, comments, online communities and reviews, to increase their knowledge and evaluate products. The aim, therefore, is to obtain information to assess vendors' trustworthiness through investigating others' experiences. Subsequently, the following hypothesis is proposed:

\section{H2: Social commerce information seeking about products is increased by trust in a SNS platform.}

\subsection{The Influence of Information Seeking on Purchase Intentions}

Information seeking in social commerce contributes considerably to customers' increasing knowledge about products through access to a significant amount of information. Thus, according to [103], the enhanced knowledge about products helps customers to facilitate the process of decision-making and increases purchase intentions. Additionally, user-generated contents (i.e. comments, reviews) in social commerce provide customers with indicative and valuable information that support their purchase decision-making and improve sales for online sellers [111]. Multimedia texts and product reviews (allowing interaction with products before purchasing) are found to have positive influence on customers' buying behaviours and increase the intention to purchase. Nonetheless, the online purchase process is characterised as uncertain and inherently risky [27]. Accordingly, information seeking is a strategy for risk reduction, boosts purchase intentions. Accordingly, the following hypothesis is suggested:

\section{H3: Information seeking has positive influence on purchase intention.}

\subsection{The Influence of Familiarity on Purchase Intention}

According to [69], familiarity is defined as current and/or past use, or knowledge obtained by attending some form of instruction or through readings on the topic (p. 964). The literature examines the influence of brand or product familiarity on customers' behaviours such as purchase intentions [82], [105], [112]. However, further investigations are required to examine the impact of familiarity with online platforms on users' perceptions. Therefore, familiarity with an online platform refers to the extent to which a customer understands the website's procedures such as familiarity with the interactions channels with others and search engines on the platform [33]. The increased knowledge about the platform decreases the degree of uncertainty about the environment. Thus, when users are familiar with a social network platform, they are expected to have confidence in the environment.

Given the context of social commerce, a purchase intention is viewed as a technical process that requires a series of steps such as searching for products, selecting online-vendors and products, placing orders, finding reviews and comments on products and online vendors and providing information [41]. Nevertheless, the execution of such activities may vary among the different platforms as these activities became more complicated. According to [31], the complexity in online shopping results in purchase resistance and avoidance. In contrast, familiarity with the platform increases users' understanding of the shopping procedures and decreases the complexity in making decisions. Such understanding, side by side with the on-going engagement with information seeking channels (i.e. communities and forums) improves users' expertise and skills about the diverse tools and aspects of the online platform, and in turn influence purchase intentions. For instance, familiarity with a platform's channels such as online-vendors' forums and reviews make users aware of rating policies, search tools, recommendations contents and the purchasing process. All these aspects can significantly influence users' purchase intentions.

Van Der Heide and Lim [100] in their study demonstrate that familiarity with a platform motivate customers to depend on their peer-generated contents to inform online purchases. On the contrary, unfamiliar customers tend not to rely on such contents. As a consequence, the following hypothesis is suggested:

H4: Familiarity with a SNS increases customers' purchase intention. 


\subsection{The Effect of Familiarity on Trust in a SNS}

Familiarity is another way that helps individuals to subjectively decrease uncertainty and streamline their relationships with others. Familiarity is often referred to as an understanding that has usually developed based on prior experiences, learning and interactions [72]. Thus, it has been argued that there is distinct difference between familiarity and trust. Specifically, familiarity represents an understanding of the current behaviours/actions of other individuals or objects, while trust is concerned with beliefs about the future behaviours/actions of other individuals or objects; these beliefs often are based on familiarity [72].

For example, familiarity with a social commerce platform denotes users' understanding and knowledge of a platform's contents/procedures, how to search for products and their information, and how to order these products through the platform interface [34]. Familiarity in this case is perceived as explicit activity-based comprehension developed through previous learning/experience of how to interact and use the platform interface. In contrast, trust in the social commerce platform might require providing credit card information based on the favourable belief of guaranty (trust) that the information is secure and will be appropriately used (even unknown) in the future.

As a result, both trust and familiarity complement each other and act as complexity-reduction mechanisms. As such, familiarity deals with reducing uncertainty by creating a structure [72]; trust, in turn, lessens uncertainty by enabling individuals to establish comparatively reliable expectations about other people's positive future actions. Thus, although familiarity and trust are fundamentally different, both are related. Familiarity provides a framework for future prospects and also permits individuals to build tangible notions and views of what to expect based on previous experience [34]. Trust is attained when prior experience is favourable, and it is absent when the prior experience is unfavourable.

Accordingly, familiarity with an SNS platform can influence trust in the platform by offering a mechanism that enables consumers to sense favourable and unfavourable expectations about the trusted party (online-vendors). Familiarity with a platform (i.e. Facebook) equips customers with skills and expertise to explore and identify others' experiences with online-vendors and products expressed by their comments, reviews and recommendations. Thus, familiarity could be the mechanism customers can rely on to evaluate the benevolence, ability and credibility of the SNS platform in order to decide whether they are willing to transact with online-vendors on the platform. Familiarity with the platform's procedures such as adequate knowledge about search engines on the platform and expertise in interaction and communication channels with peers contribute significantly to increasing trust in the platform and subsequently purchase intention. Hence, the following hypothesis is suggested:

\section{H5: Familiarity increases trust in a SNS platform}

\subsection{The Influences of Social Presence on Purchase Intention and Trust in a SNS}

The aspect of social presence emerged from the Social Presence Theory (SPT) as put forward by [94]. An explanation of the communication capacity of a medium is the main aim of SPT to convey social cues. SPT theory notes that a more effective communication is achieved when the communication medium has a certain social presence which aligns with a certain degree of interpersonal participation that is essential for performing a particular task. In his work Short et al. [94] regarded social presence as the quality of a communication medium that forms a key basis for understanding the communication between one person and another. Another definition of social presence was provided by [48] noted that it is a way of characterising the subjective experience of a user with a certain medium of communication based on the degree of emulation of the medium of face-to-face interaction. From a psychological point of view, social presence has a narrow relationship with intimacy and psychological closeness. From the psychological point of view, Gefen and Straub [31] refer social presence as the extent to which a medium of communication allowed the communicating parties to be psychologically present in the communication process. In other words, social presence is a representation of the degree to which the medium of communication makes an individual aware of the others in the communication process with the communication medium also facilitating social interaction. Another perspective of social presence is provided by Lu et al. [71] who indicated that social presence is characterised by perceived warmth, conveying a feeling of human contact, sociability, and sensitivity embodied in a medium (p.226).

According to [73], research psychology shows that human beings can be influenced and therefore can learn from the experiences and knowledge of people that they know and are aware of. Cialdini [23] noted that persuasion can be significantly effective when done by others who may be strangers. In the same way, social interactions impact the attitude, beliefs, and the behaviours of buyers when deciding on what to purchase. It has been noted that social presence has a close relationship with the richness of information [31]. With social presence, a user gains access to social knowledge, rich information, and meaningful experiences that makes them more informed and therefore allows them to make good purchasing decisions. Prior Studies [11], [58] showed that the progress of online shopping may be hindered by the absence of social presence that arises out of lack of human interaction and eventually the lack of trust. Social media platforms and social commerce therefore, consider social presence to be a key feature. In the selection of a communication channel to address an uncertain and ambiguous task such as making online 
purchases, social presence plays a key role [88]. Lu et al. [71] argues that a website with great social presence has more social cues, richer information, and considered transparent. Websites that provide high transparency promote trustworthy behaviour. Additionally, a websites social presence lowers the social distance between the sellers and the buyers which makes it easier to form trustworthy relationships. Therefore, websites with significant social presence provide online sellers with trustworthiness and maker buyers more trusting of the sellers.

Social presence is viewed as the key feature of social commerce and social media platforms [5]. Social presence is recognised as a positive factor in choosing communication channel when the task in hand is ambiguous and uncertain such as online shopping [88]. It has been argued that a great social presence on the part of a website delivers richer information and more social cues, and subsequently such websites are seen to be transparent [71]. High levels of transparency in online environments result in inhibiting untrustworthy behaviours. Charfi and Atif [14] state that social presence of a website decreases the perception of social distance between buyers and sellers. They also point out that the formation of trustworthy relationships becomes easier when perceived social distance is lessened. Hence, the social presence on websites will make online sellers more trustworthy and buyers more trusting.

Piller and Walcher [85] state that customers' recommendations and reviews allow online-sellers to establish personal connections and communications with customers. A variety of interactional tools in social commerce websites increase the sense of social presence such as Like button, comments, pictures, emoticons and reviews. A study concludes that the Like button on Facebook, which represent mere virtual presence, helps customers to improve brand assessments and purchase intention [79]. Lately, Facebook has developed a new initiative by adding reaction buttons (Emojis) (i.e. haha, love, angry, wow and sad), which show the emotional indications to peer-generated contents. Furthermore, users can convey their presence and actual feeling about the contents and keep track of animated/live reactions of peers toward a product [41]. The Tweet button on Twitter and the reaction buttons on Facebook are illustrations of social commerce mechanisms that increase users' sensitivity to relationship quality and social support [68].

The social presence of the web is referred to as the ability of a website to deliver a sense of sociability and human warmth [71] that eliminate the uncertainty involved in an online transaction [51]. Such reduction in uncertainty could significantly increase customers' trust and purchase intentions. Additionally, Gefen and Straub [30] assert that social presence boosts purchase intentions in online platforms through increasing the aspects of ability, benevolence, integrity and predictability. Furthermore, trust in SNSs is fundamentally determined by the presence of others and their observable activities [88]. Accordingly, SNSs such as Facebook that incorporate rich text, high quality picture content and multimedia content can significantly offer the means for sensitive, sociable and personal human contact. Additionally, the innovative features and emoticons of SNSs (e.g., Facebook's Emojis buttons, reviews, comments) participate significantly in improving the sense of warmth in interactions and consequently purchase intentions. Moreover, such emoticons and novel features of SNSs allow users to genuinely deliberate their presence and feeling about the various contents and discover others' active/live activities toward a product, and thus results in increased trust in SNSs. Thus, the following hypotheses are suggested:

\section{H6: Intention to purchase from online-vendors is increased by social presence.}

\section{H7: Social presence increases trust in a SNS platform}

\section{Research Methodology}

Social commerce platforms connect customers with online-vendors. However, these platforms (i.e. Twitter, Facebook) vary based on facets such as reputation, privacy policies, interaction/information sharing channels and the quantity and quality of peer-generated contents [60]. Facebook is selected as the target platform in this study. Generally, Facebook is considered one of the most popular social network sites worldwide. Furthermore, most content generation tools are provided for Facebook users. Thus, only Facebook users were selected for the purpose of this study. Participants were recruited from among undergraduate students at a private university in Jordan. According to [109], 88\% of Facebook users are 18-29 years old. Additionally, $82 \%$ of Facebook users have some college experience and $79 \%$ are graduated college students. Such figures support the selection of students as one of the most prevalent respondent sample for this study. An offline-survey method (self-administrated/paperbased survey) was employed to collect data. Only students who actively use Facebook are asked to participate in the survey. Thus, at the beginning of the survey, a screening question was asked to participants in order to discourage participants who were not Facebook users. Accordingly, a total of 550 questionnaires were sent out; 243 questionnaires were returned giving a response rate of $44.1 \%$. Of the 243 returned questionnaires, six cases with missing data were omitted. Therefore, responses from 237 participants were used to carry out the data analysis to empirically examine the research hypotheses. All participants were from the business school. Further, $57 \%$ of the participants were males and $43 \%$ were females. Additionally, most of participants (87\%) were in the age category of 18-22 years old.

Most of the measurement items used to measure the proposed model were adopted from the existing literature on ecommerce and social commerce adoption (see Table 1). All items were measured by a five-point Likert scale ranging 
from $1=$ strongly agree to $5=$ strongly disagree. Additionally, the original items were marginally adjusted to fit the case of social commerce through Facebook.

Given that the original items of the survey instrument were in English, several procedures were followed to ensure a valid translation process. Therefore, two professional translators were recruited (English-Arabic). First, the English version of the survey instrument was forwarded to translator $\mathrm{A}$, who had been asked to translate it into Arabic. Then the resultant Arabic version was sent to translator B, who was instructed to translate the Arabic version back into English. Consequently, the two English versions were discussed to create the first Arabic version of the survey. The content and readability of the initial draft of the questionnaire was checked and evaluated by four faculty members (two marketing and two electronic business and commerce) who are familiar with social media and ecommerce/social commerce research. Furthermore, independent judges who had no previous knowledge of the research aims also checked the survey. Considering the minor amendments provided by judges' and faculty members' evaluation and feedback, the survey was proven to have content validity.

Table 1: Measurement items

\begin{tabular}{|c|c|c|}
\hline Construct & Item & Source \\
\hline \multirow[t]{4}{*}{ Trust (TRU) } & TRU1: Promises made by Facebook are likely to be reliable. & \multirow[t]{4}{*}{ [33], [40], [43] } \\
\hline & TRU2: I do not doubt the honesty of Facebook & \\
\hline & TRU3: Based on my experience with Facebook, I know it is honest. & \\
\hline & $\begin{array}{l}\text { TRU4: Based on my experience with Facebook, I know they care } \\
\text { about users. }\end{array}$ & \\
\hline \multirow{3}{*}{$\begin{array}{c}\text { Familiarity } \\
\text { (FAM) }\end{array}$} & FAM1: I am familiar with searching for materials in Facebook. & \multirow[t]{3}{*}{ [34], [43] } \\
\hline & FAM2: I am familiar with buying materials in Facebook. & \\
\hline & $\begin{array}{l}\text { FAM3: I am familiar with inquiring about material ratings in } \\
\text { Facebook. }\end{array}$ & \\
\hline \multirow{4}{*}{$\begin{array}{c}\text { Social } \\
\text { Commerce } \\
\text { Information } \\
\text { Seeking (SCl) }\end{array}$} & $\begin{array}{l}\text { SCI1: I use online forums and communities for acquiring information } \\
\text { about a product. }\end{array}$ & \multirow[t]{4}{*}{ [37], [43] } \\
\hline & $\begin{array}{l}\text { SCI2: I usually use people ratings and reviews about products on } \\
\text { the internet. }\end{array}$ & \\
\hline & $\begin{array}{l}\text { SCI3: I usually use people's recommendations to buy a product on } \\
\text { the internet. }\end{array}$ & \\
\hline & SCI4: I trust my friends on online forums and communities & \\
\hline \multirow{4}{*}{$\begin{array}{c}\text { Social } \\
\text { Presence } \\
\text { (SOP) }\end{array}$} & SOP1: There is a sense of human contact in Facebook. & \multirow[t]{4}{*}{ [30], [43], [71], [81] } \\
\hline & SOP2: There is a sense of sociability in Facebook. & \\
\hline & SOP3: There is a sense of human warmth in Facebook & \\
\hline & SOP4: There is a sense of human sensitivity in Facebook. & \\
\hline \multirow{2}{*}{$\begin{array}{l}\text { Purchase } \\
\text { Intention } \\
\text { (PINT) }\end{array}$} & $\begin{array}{l}\text { PINT1: I am very likely to provide the online vendor with the } \\
\text { information it needs to better serve my needs through Facebook }\end{array}$ & \multirow[t]{2}{*}{ [33], [43], [75] } \\
\hline & $\begin{array}{l}\text { PINT2: I am happy to use my credit card to purchase from an online } \\
\text { vendor through Facebook. }\end{array}$ & \\
\hline
\end{tabular}

\section{Data Analysis}

Structural equation modelling (SEM) was utilised to analyse data. Specifically, partial least square SEM (PLS-SEM) was selected for this research for various reasons. In particular, PLS-SEM stresses exploration and prediction, is capable of handling multifaceted models, and concurrently lessens the demands and requirements with regard to data and the specification of relationships [87]. Additionally, PLS-SEM is appropriate when it comes to explaining complex relationships or models, and is also better in terms of serving exploratory and predictive goals [86]. Moreover, Gefen [34] indicate that PLS-SEM is appropriate for testing new models and theories as it can be utilised for both exploratory and confirmatory studies. Hence, given that this study is exploratory in nature, and also because it is designed to test a proposed model, it was believed that PLS-SEM was the most suitable method. Following the recommendation of Henseler et al. [46], a sequential two-steps analysis was adopted to test the proposed paths of the study model, including: 1) the measurement model stage and 2) the structural model stage. 


\subsection{Measurement Model}

In this stage, both reliability and validity are assessed. To ensure that the dataset is valid and reliable, it is essential to examine: 1) the reliability of individual items and constructs; and 2), discriminant and convergent validity. The individual reliability of each item is weighted by the squared standardised loading of each item. Hair et al. [35] point out that the squired loading coefficient of each individual item that relates to a theoretical construct should be $\geq 0.5$.

As Table 2 shows, all items have squired standardised loading $\geq 0.5$, and in turn it can be concluded that individual reliability was acquired for all items. Reliability of each construct was examined by evaluating the coefficients of both Cronbach's $\alpha$ and composite reliability. All constructs have adequate internal consistency, as all constructs acquired Cronbach's $\alpha$ and composite reliability $>0.7$ (see Table 2) [63]. Convergent validity was examined by assessing the average variance extracted (AVE) coefficient [35]. As can be demonstrated in Table 2, all constructs have AVE value $\geq 0.5$, indicating that each construct explains as a minimum $50 \%$ of the variance of its related theoretical items.

Table 2: Measurement model assessment

\begin{tabular}{|c|c|c|c|c|c|c|}
\hline Construct & Item & Item Loading & $\begin{array}{l}\text { Square Item's } \\
\text { Loading }\left(\mathbf{R}^{2}\right)\end{array}$ & $\alpha^{a}$ & $\mathrm{CR}^{\mathrm{b}}$ & AVE $^{c}$ \\
\hline \multirow[t]{4}{*}{ Trust (TRU) } & TRU1 & 0.91 & 0.83 & \multirow{4}{*}{0.92} & \multirow{4}{*}{0.94} & \multirow{4}{*}{0.80} \\
\hline & TRU2 & 0.92 & 0.85 & & & \\
\hline & TRU3 & 0.90 & 0.81 & & & \\
\hline & TRU4 & 0.87 & 0.76 & & & \\
\hline \multirow[t]{3}{*}{ Familiarity (FAM) } & FAM1 & 0.93 & 0.86 & \multirow{3}{*}{0.90} & \multirow{3}{*}{0.94} & \multirow{3}{*}{0.84} \\
\hline & FAM2 & 0.90 & 0.81 & & & \\
\hline & FAM3 & 0.91 & 0.83 & & & \\
\hline \multirow{4}{*}{$\begin{array}{l}\text { Social Commerce } \\
\text { Information } \\
\text { Seeking (SCI) }\end{array}$} & $\mathrm{SCl} 1$ & 0.87 & 0.76 & \multirow{4}{*}{0.89} & \multirow{4}{*}{0.92} & \multirow{4}{*}{0.74} \\
\hline & $\mathrm{SCl} 2$ & 0.85 & 0.72 & & & \\
\hline & $\mathrm{SCl} 3$ & 0.84 & 0.71 & & & \\
\hline & $\mathrm{SCl} 4$ & 0.89 & 0.79 & & & \\
\hline \multirow{4}{*}{$\begin{array}{l}\text { Social Presence } \\
\text { (SOP) }\end{array}$} & SOP1 & 0.88 & 0.77 & \multirow{4}{*}{0.91} & \multirow{4}{*}{0.93} & \multirow{4}{*}{0.78} \\
\hline & SOP2 & 0.90 & 0.81 & & & \\
\hline & SOP3 & 0.87 & 0.76 & & & \\
\hline & SOP4 & 0.89 & 0.79 & & & \\
\hline \multirow{2}{*}{$\begin{array}{l}\text { Purchase Intention } \\
\text { (PINT) }\end{array}$} & PINT1 & 0.95 & 0.90 & \multirow{2}{*}{0.87} & \multirow{2}{*}{0.93} & \multirow{2}{*}{0.89} \\
\hline & PINT2 & 0.93 & 0.86 & & & \\
\hline
\end{tabular}

a: Cronbach's $\alpha$, b:composite reliability, c: average variance extracted

To claim that the constructs of the research model demonstrate adequate discriminant validity, it was fundamental that the shared variance between each construct and its items must be higer than the shared variance between the construct and the other constructs [35]. Thus, discriminant validity was evaluated by the criterion of Fornell and Larcker [28]. The criterion suggests that the squared root of AVE value for a construct must be higher than any correlation between the construct and other constructs. As can be demonstrated in Table 3, the squared root of AVE for each construct is significantly higher than correlations with all other constructs. Hence, discriminant validity is presented in this study.

Table 3: Discriminant validity

\begin{tabular}{|l|l|l|l|l|l|l|l|l|}
\hline & & \multicolumn{6}{|c|}{ Latent variable correlations } \\
\hline Construct & AVE & $\sqrt{\text { AVE }}$ & & \multicolumn{1}{|c|}{ TRU } & FAM & SCI & SOP & PINT \\
\hline TRU & 0.80 & 0.89 & TRU & 1 & & & & \\
\hline FAM & 0.84 & 0.92 & FAM & 0.389 & 1 & & & \\
\hline SCI & 0.74 & 0.86 & SCI & 0.386 & 0.379 & 1 & & \\
\hline SOP & 0.78 & 0.88 & SOP & 0.220 & 0.243 & 0.192 & 1 & \\
\hline PINT & 0.89 & 0.94 & PINT & 0.456 & 0.404 & 0.384 & 0.428 & 1 \\
\hline
\end{tabular}

\subsection{Structural Model}

Once the reliability and validity of the dataset were established, the next stage was to examine the hypothesised paths. In this step, both of the explanatory power $\left(R^{2}\right)$ and bath coefficients $(\beta)$ of the proposed paths were identified. As Figure 2 illustrates, $R^{2}$ for PINT is 0.377 , which demonstrates that social presence (SOP), trust (TRU), information seeking (SCI) and familiarity (FAM) and explain $37.7 \%$ of the variance in purchase intention (PINT). Furthermore, both FAM and SOP explain $16.8 \%$ of the variance in trust (TRU) $\left(R^{2}=0.168\right)$. Finally, TRU explains $14.9 \%$ of the variance in $\mathrm{SCl}\left(\mathrm{R}^{2}=0.149\right)$. Regarding the path analysis, TRU $(\beta=0.262)$, FAM $(\beta=0.168)$, SOP $(\beta=0.298)$ and $\mathrm{SCI}(\beta=0.162)$ were found to act as facilitators of PINT, as all have positive significant effects on PINT. 
Additionally, both FAM $(\beta=0.356)$ and SOP $(\beta=0.134)$ act as important antecedents of TRU, as both have positive significant effects on TRU. TRU was found to be a vital predictor of $\mathrm{SCl}$, as it has positive significant effect $(\beta=0.386)$ on SCl.

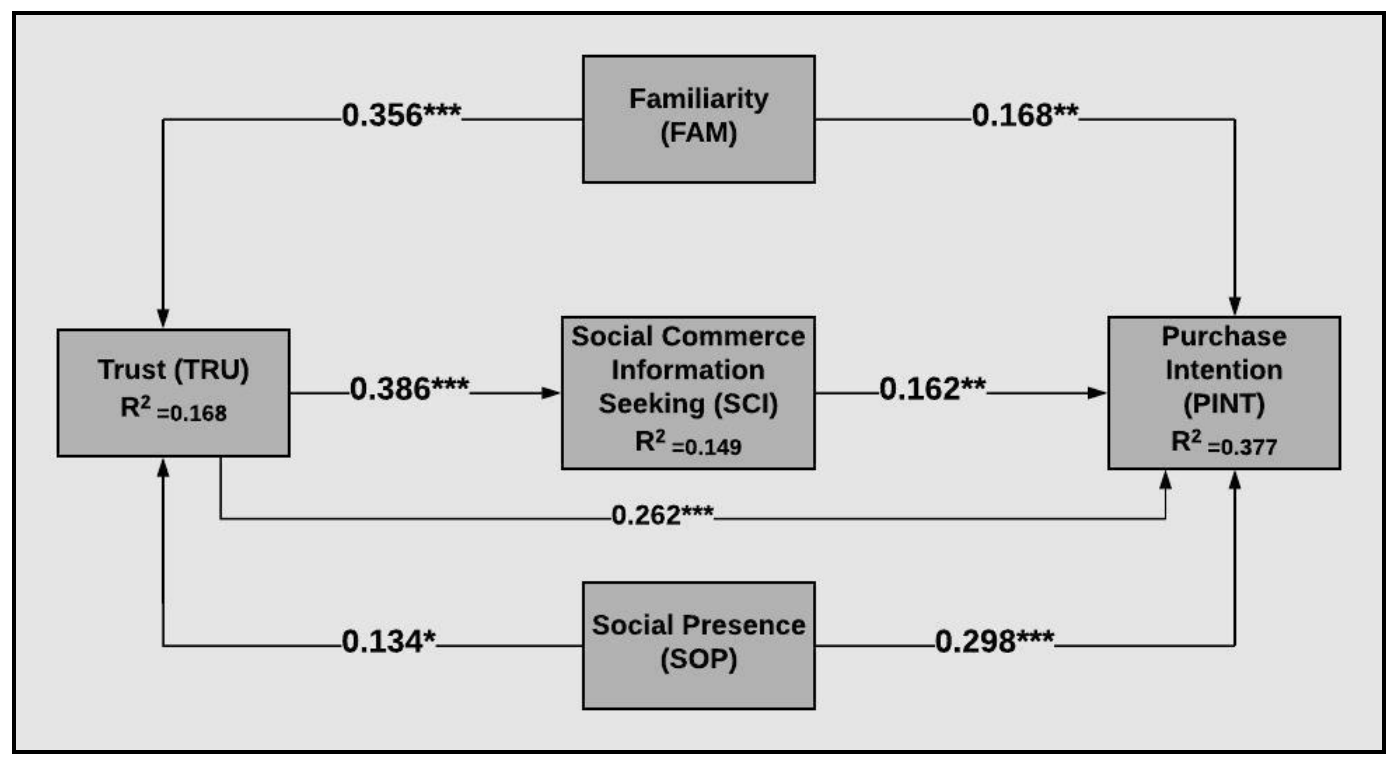

Figure 2: Structural model results

${ }^{*} \mathrm{P}$ value $>0.05,{ }^{* *} \mathrm{P}$ value $>0.01,{ }^{* * *} \mathrm{P}$ value $>0.001$

\subsection{Mediation}

A Sobel [95] test was performed to conclude whether mediators significantly convey the effects of independent variables to dependent variables. As indicated in Table 4, the results of Sobel test show that all indirect effects are significant. Beside its direct effect, TRU is found to have significant indirect effect on PINT through SCl. The test indicates that SCl carries the influence of TRU to PINT. This signifies the curtail role of TRU in increasing PINT. Such finding suggests that the increase in TRU will enhance the perceptions of SCI and subsequently will positively influence PINT. Furthermore, both FAM and SOP have indirect significant effects on PINT through TRU. This demonstrates that the increase in FAM and SOP will boost the perception of TRU, and in turn enhances PINT.

Table 4: Mediation test

\begin{tabular}{|l|l|l|l|}
\hline Mediator & Path & T-statistic & $\boldsymbol{P}$-value \\
\hline SCI & TRU $\rightarrow$ SCI $\rightarrow$ PINT & 4.5 & $<0.001$ \\
\hline TRU & FAM $\rightarrow$ TRU $\rightarrow$ PINT & 5.2 & $<0.001$ \\
\hline TRU & SOP $\rightarrow$ TRU $\rightarrow$ PINT & 4.18 & $<0.001$ \\
\hline
\end{tabular}

\section{Discussion}

The current study was conducted to investigate the role of trust in a SNS platform in influencing customers' behavioural intentions to purchase from e-sellers through Facebook social commerce in Jordan. Specifically, this study proposed a framework to explain the relationship between trust in a SNS platform and customers' purchase intention. The framework consisted of three additional constructs: social presence, social commerce information seeking and familiarity with the platform. Facebook, as one of the most popular SNS, was chosen to empirically test the research model. Similar to [41], [73], trust in a SNS platform has a positive influence on both purchase intention and social commerce information seeking. This finding demonstrates that the more customers have trust in an SNS, the more likely they will have positive intention to purchase. According to [92], trust plays a fundamental role in steering customers' behavioural intention and actual behaviour. Particularly, trust is deemed to be more important when risk and uncertainty perceptions are high, as in the context of online-shopping. Social trust has also received considerable attention as it has been viewed as an essential element to evaluating systems' reliability [38]. Social trust reduces transaction costs and decreases the propensity to monitor and observe other parties' activities. In an uncertain environment where individuals interact anonymously such as in online transactions, high degrees of social trust can effectively smoothen the process of exchange between them. Social technologies offered by SNS platforms (i.e. customers' reviews, comments, recommendations and ratings) enable customers to establish social activities, which in turn result in increased social trust among connected customers and in decreasing their risk and 
overcoming uncertainty [45]. Do-Hyung et al. [24] suggest that information acquired from customers' reviews is considered to be more trustworthy than information provided by online-vendors. Consequently, when customers believe that a SNS platform is a reliable source of social trust, their trust in the platform will be increased and, in turn, they will develop a favourable intention to purchase. Moreover, the findings indicate that trust in a SNS platform is an essential requirement to encourage customers to seek information and follow contents generated by the various communication channels of the platform. Once trust in the SNS and its content trustworthiness are established, customers are motivated to navigate through and use the available sources to enrich their knowledge to effectively assess products and services. Furthermore, trust in SNS platforms facilitates the process of investigating the trustworthiness of online-vendors through the exploration of previous experiences of other customers.

In agreement with [56], [83] the impact of social commerce information seeking has been found positive on consumers' purchase intention. Online social influence is an essential aspect of social commerce. By communicating about online-vendors, products and services, information seekers (or opinion seekers) are motivated to reinforce or to generate relationships with a group, and thus they are becoming indirectly more open to normative influences. Previous research has found that social information seeking influences brands and sales choice. Additionally, it has been found that customers who tend to consult online product recommendations are more likely to purchase recommended products than those who do not consult recommendations [89]. Ishida et al. [53] point out that online consumers intend to give and seek information similar to the ways they do in offline contexts, which influences the sales of many services and products.

Social commerce information seeking helps customers to fulfil their needs to enhance products, services and onlinevendors choice and to lessening risk perception. In doing so, customers, through social commerce information seeking mechanisms (i.e. reviews, recommendations, comments, ratings), acquire holistic understanding about online-vendors and products which in turn improve their purchase decision making. Thus, customers who intend to use online social shops and to share their opinions and recommendations are more likely to seek information via SNSs [110]. Accordingly, social commerce information seeking is related to holding favourable attitudes and intent to social commerce purchasing. Information seeking participation significantly increases customers' seniority and familiarity in terms of active and frequent use of a SNS platform. Customers are actively seeking information about products and online-vendors. Such processes require customers to navigate through various communication channels (i.e. recommendations, reviews, comments, search engines) on a SNS platform, which in turn enhance knowledge and expertise about the functionality and different features of the platform.

Contrary to [78] and consistent with [21], [41], social presence has positively affected customers' purchase intention. Furthermore, in agreement with [30], [40], social presence has considerably influenced trust in a SNS. The findings suggest that the stronger the social presence of a SNS, the stronger customers' purchase intention and trust in the SNS platform will be. It has been noted that when online consumers shopping, they struggle to assess the validity of information provided by an online-seller. Nonetheless, online consumers can actively seek indirect cues from their peers who have previously purchased from the same online-seller. Such social cues allow customers to observe others' purchase actions and reactions, which in turn reduce uncertainty by providing rich and transparent information that influence customers' purchase intention. In addition, increased levels of social presence in a SNS platform include an individual to whom grievances and queries can be addressed. This posits that online-vendors on the platform are not hiding information and avoiding opportunistic and untrustworthy behaviours, and thus customers' purchase intention will be positively influenced. On the other hand, customers' trust in a SNS platform can be attained when the social presence of the platform (i.e. rich text, pictures and multimedia contents), social presence of online-sellers (i.e. chatting and interaction with sellers) and social presence of other consumers (i.e. comments, reviews, ratings, recommendations) are present.

Similar to [34], [40] the influence of familiarity has been found positive on customers' trust in a SNS platform. Additionally, consistent with [41], familiarity has acted a facilitator of customers' purchase intention. Such findings highlight the important influence of familiarity in social commerce context. The more customers are familiar with a SNS platform, the more they trust the platform and the more they have positive purchase intention. An increased degree of familiarity with a SNS decreases ambiguity in online shopping as it helps customers to acquire better understanding of the online environment. Increased familiarity with a SNS facilitates searching information (i.e. comments, rating, forums) related to products, services and online-vendors and the platform's procedures. As a result, it equips customers with sufficient information and knowledge about others' experiences with regards to purchases, and subsequently can positively influence customers' purchase intentions. Additionally, such knowledge and expertise created by familiarity allows customers to build trust in a SNS. Customers who are familiar with a SNS are able to find the desired information required for their purchases, and as a consequence they can sense the trustworthiness of the SNS as a source of significant information. Familiarity, as an important element of sensing trust in a SNS, contributes to equipping customers with the experience and skills to discover and navigate others' experiences with online-vendors and products, reflected by their comments, reviews and recommendations that are fundamental for purchase intention. Thus, increased familiarity leads to developing customers' ability to retain certainty and trust in a SNS; or in contrast, a lack of familiarity results in decreasing the acquisition of essential purchase information, and consequently a lack of trust in a SNS. 


\section{Implications and Future Work}

The findings presented in the previous section offer numerous managerial and research implications for social commerce and firms' managers. From a managerial perspective, trust is recognised as an important issue in social commerce environments. It significantly has an important role to play in boosting purchase intentions. Furthermore, increased trust in SNS platforms results in greater customer engagement in the process of purchasing. Thus, both SNSs and social commerce designers should enhance customers' trust by improving the characteristics and features of the platforms. This includes enhanced information quality, reputation, transaction safety and communications. The findings also demonstrate that the act of seeking information in a social commerce platform has positive consequences on customers' purchase intentions. Customers use various information channels on social commerce platforms to obtain the information required to guide their purchase decisions. As a result, if online-vendors want to increase purchase intentions within their forums and communities, they should offer easy access to information channels, search engines, information exchange process and improve trust in provided contents. Customers' engagement in forums, recommendations, communities, ratings and reviews should ease information seeking and communications with peers. Accordingly, SNS firms should bear in mind that enhancing the integration of resources among online-vendors and peers can be achieved by improving the process of information seeking. Therefore, as suggested by [41], connecting search engines with SNSs can assist the search process. Nevertheless, Van Der Heide and Lim [100] point out that familiarity with a SNS platform enables customers to rely on the platform's embedded contents to inform purchase decisions.

The findings indicate that social presence effectively improves customers' purchase intention and trust in social commerce platforms. Thus, online-vendors, SNS and social commerce firms should invest in building and sustaining effective IT artefacts that address and support the various dimensions of social presence (social presence of web, seller and peers). For instance, incorporating visual elements (avatars and Facebook GIF buttons and animated reactions) to forums, pages and communities can effectively increase social presence. In addition, familiarity plays an essential role in enhancing both customers' purchase intentions and trust in social commerce platforms. The more customers are familiar with a SNS platform, the more they are able to acquire the information to assess their purchase decisions. As a consequence, this finding confirms the need for SNS firms to make the process as usable as possible since such tactics will also attract less familiar customers. Therefore, SNS and social commerce firms should educate customers by offering various learning means, including online-chatting, educational taps, specialised online customer support, video demonstrations and clear guidelines. Online-vendors should make sure that their sites are intuitive and easy to use. They should also actively provide their pages with graphical instructions, FAQs, speech-bubbles and supportive tips about the page's new features.

In terms of research implications, most previous e-commerce and social commerce research has focused on the effect of information exchange, social presence and familiarity on trust and its behavioural consequences. Previous research posits that web experience and familiarity are the main antecedents of trusting beliefs [31], [33]. However, the conceptual model of this study suggests that this process is not always the case in social commerce platforms. The research model investigates the impact of familiarity and social presence on both trust and purchase intentions. Additionally, it conceptualises trust as the key determinant of information seeking, which directly influences purchase intentions and mediates the influence of trust on purchase intentions through familiarity.

The current study has been subjected to several limitations and therefore calls for future research. Facebook was the context of this study as one of the most popular SNS platform. Such limitation calls for future research to validate the research model with other SNSs (i.e. Instagram, Twitter). Furthermore, this study is based on cross-sectional data to examine the conceptual model. Experimental and longitudinal studies are required to investigate the effect of trust on purchase intentions. The current study adopted a quantitative data collection method. Studies with a mixed methods approach are required to reveal more potential factors and moderators that may influence purchase intention [3].

\section{Conclusion}

This study shed light onto a novel social commerce adoption model and aimed to understand its determinants and consequences. The aim of this study was to identify the role of trust in a SNS platform in influencing customers' behavioural intention to purchase from e-sellers through Facebook social commerce in Jordan. Specifically, the research model investigated how the interaction between trust in a SNS platform, familiarity with the platform, social commerce information seeking and social presence affect and shape customers' intentions to purchase from esellers through Facebook social commerce. Based on the empirical results, familiarity, social presence, trust and social commerce information seeking have direct positive influences on social purchase intentions. Additionally, both familiarity and social presence were found to strengthen trust, and thus both have indirect positive impacts on purchase intentions through trust. Furthermore, social commerce information seeking was found to improve customers' familiarity with a social commerce platform, and subsequently it has indirect positive influence on purchase intentions through familiarity. Besides its crucial direct influence on purchase intentions, trust was found to be a significant motivator that encourages customers to seek social commerce information, thus it also has indirect positive influence on purchase intentions through social commerce information seeking. Finally, the rich findings 
obtained from this study contribute to the related literature and offer actionable insights with valuable implications for SNSs designers, firms and social commerce managers.

\section{Acknowledgments}

We would like to thank the Business School at Al Ahliyya Amman University, Jordan. Specifically, many thanks go to the departments of Information Systems and Electronic Commerce. Furthermore, we would like to thank Dr. Amer AlAdwan from Hamad Bin Khalifa University, Qatar for his support and useful guidance.

\section{References}

[1] S. Ahmad and M. Laroche, Analyzing electronic word of mouth: A social commerce construct, International Journal of Information Management, vol. 37, no. 3, pp. 202-213, 2017.

[2] I. Ajzen, The theory of planned behavior, Organizational Behavior and Human Decision Processes, vol. 50, no. 2, pp. 179-211, 1991.

[3] A. Al Adwan, A. Case study and grounded theory: A happy marriage? An exemplary application from healthcare informatics adoption research, International Journal of Electronic Healthcare, vol. 9, no. 4, pp. 294318, 2017.

[4] A. Al-Adwan, Alrousan, A. Al-Soud, and H. Al-Yaseen, Revealing the black box of shifting from electronic commerce to mobile commerce: The case of Jordan, Journal of Theoretical and Applied Electronic Commerce Research, vol.14, no.1, pp.51-67, 2019.

[5] A. Al-Adwan, Novel research framework for social commerce purchase intentions, Journal of Theoretical and Applied Information Technology, vol. 96, no.14, pp. 4390-4404, 2018.

[6] S. Alwi and T. Wook, Social presence model for e-commerce, Jurnal Teknologi, vol. 77, no. 1, pp.71-83, 2015.

[7] N. Amblee and T. Bui, Harnessing the influence of social proof in online shopping: The effect of electronic word of mouth on sales of digital microproducts, International Journal of Electronic Commerce, vol. 16, no. 2, pp. 91$114,2011$.

[8] Arab Advisor Group, (2012, March) Jordan internet users and e-commerce survey 2012. Arab Advisors Group. [Online]. Available: http://www.arabadvisors.com/jordan-internet-users-and-e-commerce-survey-2012-1

[9] Y. Bai, Z. Yao and Y. Dou, Effect of social commerce factors on user purchase behaviour: An empirical investigation from renren.com, International Journal of Information Management, vol. 35, no. 5, pp. 538-550, 2015.

[10] N. Barnes, Social commerce emerges as big brands position themselves to turn follows, likes and pins into sales, American Journal of Management, vol. 14, no. 4, pp. 11-18, 2014.

[11] E. Botha and M. Reyneke, The influence of social presence on online purchase intention: An experiment with different product types, in looking forward, looking back: Drawing on the past to shape the future of marketing. Developments in marketing science, in Proceedings of the Academy of Marketing Science, Monterey, 2013, pp.180-184.

[12] A. Busalim and Hussin, Understanding social commerce, International Journal of Information Management, vol. 36, no. 6, pp.1075-1088, 2016.

[13] Y. Chang and S. Fang, Antecedents and distinctions between online trust and distrust: Predicting high-and lowrisk internet behaviors, Journal of Electronic Commerce Research, vol. 14, no. 2, pp. 149-166, 2013.

[14] A. Charfi and Atif, Virtual agent: A determinant of online social presence and consumer trust in websites, International Journal of Economic Practices and Theories, vol. 4, no. 5, pp. 796-806, 2014.

[15] Y. Chen and J. Xie, Online consumer review: Word-of-mouth as a new element of marketing communication mix, Management Science, vol. 54, no. 3, pp. 477-491, 2008.

[16] L. Chen and R. Wang, Trust development and transfer from electronic commerce to social commerce: an empirical investigation, American Journal of Industrial and Business Management, vol. 6, no. 5, pp. 568-576, 2016.

[17] J. Chen and X. Shen, Consumers' decisions in social commerce context: An empirical investigation, Decision Support Systems, vol. 79, no. 1, pp. 5-64, 2015.

[18] Y. Chen, Q. Wang and J. Xie, Online social interactions: a natural experiment on word of mouth versus observational learning, Journal of Marketing Research, vol. 48, no. 2, pp. 238-254, 2011.

[19] V. Cheng, J. Rhodes and P. Lok, The relationship between online reviews, brand trust, and willingness to buy, in Strategic E-Commerce Systems and Tools for Competing in the Digital Marketplace (M. Khosrow-Pour, Ed.). Hershey: IGI Global, 2015, pp. 139-162.

[20] Y. Cho and E. Sagynov, Exploring factors that affect usefulness, ease of use, trust, and purchase intention in the online environment, International Journal of Management \& Information Systems, vol. 19, no. 1, pp. 21-36, 2015.

[21] H. Choi, J. Lee and Y. Kim, The influence of social presence on customer intention to reuse online recommender systems: The roles of personalization and product type, International Journal of Electronic Commerce, vol. 16, no. 1, pp. 129-154, 2011.

[22] F. Chu and X. Zhang, Satisfaction, trust and online purchase intention: A study of consumer perceptions, in Proceedings The 6th Logistics, Informatics and Service Sciences (LISS), Australia, Sydney, 2016, pp. 1-4.

[23] R. Cialdini, Harnessing the science of persuasion, Harvard Business Review, vol. 79, no. 9, pp. 72-81, 2001. 
[24] E. Do-Hyung, L. Jumin and H. Ingoo, The effect of on-line consumer reviews on consumer purchasing intention: the moderating role of involvement, International Journal of Electronic Commerce, vol. 11, no. 4, pp. 125-148, 2007.

[25] L. Esmaeili, M. Mutallebi, S. Mardani, and S. Golpayegani, Studying the affecting factors on trust in social commerce, International Journal of Advanced Studies in Computer Science and Engineering, vol. 4, no. 6, pp. 41-46, 2015.

[26] Y. Fang, I. Qureshi, H. Sun, H. McCole, E. Ramsey, and K. Lim, Trust, satisfaction, and online repurchase intention: the moderating role of perceived effectiveness of e-commerce institutional mechanisms, MIS Quarterly, vol. 38, no. 2, pp. 407-427, 2014.

[27] M. Featherman and N. Hajli, Self-service technologies and e-services risks in social commerce era, Journal of Business Ethics, vol. 139, no. 2, pp. 251-269, 2016.

[28] C. Fornell and F. Larcker, Evaluating structural equation models with unobservable variables and measurement error, Journal of Marketing Research, vol. 18, no. 1, pp. 39-50, 1981.

[29] S. Gabbriellini and F. Santini, A micro study on the evolution of arguments in amazon. com's reviews, in Proceedings 18th International Conference on Principles and Practice of Multi-Agent Systems, Bertinoro, Italy, 2015, pp. 284-300.

[30] D. Gefen and D. Straub, Consumer trust in B2C e-commerce and the importance of social presence: Experiments in e-products and e-services, Omega, vol. 32, no. 6, pp. 407-424, 2004

[31] D. Gefen and D. Straub, Managing user trust in B2C e-service, e-Service Journal, vol. 2, no. 2, pp. 7-24, 2003.

[32] D. Gefen and P. Pavlou, The boundaries of trust and risk: The quadratic moderating role of institutional structures, Information Systems Research, vol. 23, no. 3, pp. 940-959, 2012.

[33] D. Gefen, E. Karahanna and D. Straub, Trust and TAM in online shopping: An integrated model, MIS Quarterly, vol. 27, no.1, pp. 51-90, 2003

[34] D. Gefen, E-commerce: The role of familiarity and trust, Omega, vol. 28, no. 6, pp. 725-737, 2000.

[35] F. Hair, G. Hult and M. Ringle, A Primer on Partial Least Squares Structural Equation Modelling (PLS-SEM). Thousand Oaks, CA: Sage Publication, 2013.

[36] R. Griffin, S. Dunwoody and K. Neuwirth, Proposed model of the relationship of risk information seeking and processing to the development of preventive behaviors, Environmental Research, vol. 80, no. 2, pp. S230S245,1999.

[37] N. Hajli and J. Sims, Social commerce: The transfer of power from sellers to buyers, Technological Forecasting and Social Change, vol. 94, no. 1, pp. 350-358, 2015.

[38] M. Hajli, A research framework for social commerce adoption, Information Management \& Computer Security, vol. 21, no. 3, pp. 144-154, 2013.

[39] M. Hajli, A study of the impact of social media on consumers, International Journal of Marketing Research, vol. 56, no. 3, pp. 386-404, 2014.

[40] M. Hajli, An integrated model for e-commerce adoption at the customer level with the impact of social commerce, International Journal of Information Science and Management (IJISM), Special Issue 1, pp. 77-97, 2012.

[41] N. Hajli, J. Sims, A. Zadeh, and M. Richard, A social commerce investigation of the role of trust in a social networking site on purchase intentions, Journal of Business Research, vol. 71, no. 1, pp. 133-141, 2017a.

[42] N. Hajli, Social commerce constructs and consumer's intention to buy, International Journal of Information Management, vol. 35, no. 2, pp. 183-191, 2015.

[43] N. Hajli, Y. Wang, M. Tajvidi, and M. Hajli, People, technologies, and organizations interactions in a social commerce Era, IEEE Transactions on Engineering Management, vol. 64, no. 4, pp. 594-604, 2017b.

[44] M. Halaweh, Adoption of e-commerce in Jordan: Understanding the security challenge, The Electronic Journal of Information Systems in Developing Countries, vol. 47, no. 1, pp. 1-13, 2011

[45] B. Han and J. Windsor, User's willingness to pay on social network sites, Journal of Computer Information Systems, vol. 51, no. 4, pp. 31-40, 2011.

[46] J. Henseler, C. Ringle and R. Sinkovics, The use of partial least squares path modelling in international marketing, Advances in International Marketing, vol. 20, no. 1, pp. 277-319, 2009.

[47] M. Hertzum, H. Andersen, V. Andersen, and C. Hansen, Trust in information sources: Seeking information from people, documents, and virtual agents, Interacting with Computes, vol. 14, no. 5, pp. 575-599, 2002.

[48] T. Hess, M. Fuller and D. Campbell, Designing interfaces with social presence: Using vividness and extraversion to create social recommendation agents, Journal of the Association for Information Systems, vol. 10, no. 12, pp. 889-919, 2009.

[49] H. Hettiarachchi, C. Wickramasinghe and S. Ranathunga, The role of social commerce on consumer Decisions: A theoretical foundation, Journal of Business and Technology. vol. 1, no. 2, pp.120-139, 2017

[50] Z. Huang and M. Benyoucef, From e-commerce to social commerce: A close look at design features, Electronic Commerce Research and Applications, vol. 12, no. 4, pp. 246-259, 2013.

[51] I. Hwang, B. Lee and K. Kim, Information asymmetry, social networking site word of mouth, and mobility effects on social commerce in Korea, Cyberpsychology, Behavior and Social Networking, vol. 17, no. 2, pp. 117-124, 2014

[52] N. Indiani, I. Rahyuda, N.Yasa, and I. Sukaatmadja, Perceived risk and trust as major determinants of actual purchase, transcending the influence of intention, Asian Marketing Journal, vol. 7, no. 1, pp. 1-13, 2015.

[53] K. Ishida, L. Slevitch and K. Siamionava, The effects of traditional and electronic word-of-mouth on destination image: A case of vacation tourists visiting Branson, Missouri, Administrative Sciences, vol. 6, no. 4, pp. 1-17, 2016. 
[54] S. Jarvenpaa, N. Tractinsky and L. Saarinen, Consumer trust in an internet store, Information Technology and Management, vol. 1, no. 2, pp. 45-71, 2000.

[55] L. Jia, C. Cegielski and Q. Zhang, The effect of trust on customers' online repurchase intention in consumer-toconsumer electronic commerce, Journal of Organizational and End User Computing (JOEUC), vol. 26, no. 3, pp. 65-86, 2014.

[56] S. Kaiser and G. Müller-Seitz, Leveraging lead user knowledge in software development: The case of weblog technology, Industry and Innovation, vol. 15, no. 2, pp. 199-221, 2008.

[57] J. Kang, K. Johnson and J. Wu, Consumer style inventory and intent to social shop online for apparel using social networking sites, Journal of Fashion Marketing and Management, vol. 18, no. 3, pp. 301-320, 2014.

[58] F. Karimov, M. Brengman and L. Hove, The effect of website design dimensions on initial trust: a synthesis of the empirical literature, Journal of Electronic Commerce Research, vol. 12, no. 4, pp. 272-301, 2011.

[59] K. Kaur and S. Kumar, S-commerce: An empirical analysis to study the consumers buying behavior, International Journal of Management Studies, vol. 1, no. 4, pp. 77-83, 2018.

[60] S. Kim and H. Park, Effects of various characteristics of social commerce (s-commerce) on consumers' trust and trust performance, International Journal of Information Management, vol. 33, no. 2, pp. 318-332, 2013.

[61] C. Kuhlthau, Inside the search process: Information seeking from the user's perspective, Journal of the Association for Information Science and Technology, vol. 42, no. 5, pp. 361-371, 1991

[62] K. Kwahk and B. Kim, Effects of social media on consumers' purchase decisions: Evidence from Taobao, Service Business, vol. 11, no. 4, pp. 803-829, 2017.

[63] K. Kwong and K. Wong, Partial least squares structural equation modelling (PLS-SEM) techniques using SmartPLS, Marketing Bulletin, vol. 24, no. 1, pp.1-32, 2013.

[64] L. Lai and E. Turban, Groups formation and operations in the Web 2.0 environment and social networks, Group Decision and Negotiation, vol. 17, no. 5, pp. 387-402, 2008.

[65] P. Lal, Analysing determinants influencing an individual's intention to use social commerce website, Future Business Journal, vol. 3, no. 1, pp. 70-85, 2017.

[66] R. Li, J. Kim and J. Park, The effects of internet shoppers' trust on their purchasing intention in China, JISTEMJournal of Information Systems and Technology Management, vol. 4, no. 3, pp. 269-286, 2007.

[67] T. Liang and E.Turban, Introduction to the special issue social commerce: A research framework for social commerce, International Journal of Electronic Commerce, vol. 16, no. 2, pp. 5-14, 2011.

[68] T. Liang, Y. Ho, Y. Li, and E. Turban, What drives social commerce: The role of social support and relationship quality, International Journal of Electronic Commerce, vol. 16, no. 2, pp. 69-90, 2011.

[69] M. Liberatore and G. Titus, The practice of management science in R\&D project management, Management Science, vol. 29, no. 8, pp. 962-974, 1983.

[70] Y. Lu, L. Zhao and B. Wang, From virtual community members to C2C e-commerce buyers: Trust in virtual communities and its effect on consumers' purchase intention, Electronic Commerce Research and Applications, vol. 9, no. 4, pp. 346-360, 2010.

[71] B. Lu, W. Fan and M. Zhou, Social presence, trust, and social commerce purchase intention: An empirical research, Computers in Human Behaviour, vol. 56, no. 1, pp. 225-237, 2016.

[72] N. Luhmann, Trust and Power. Cambridge: John Willey \& Sons, 1979.

[73] P. Marsden. (2010) Social commerce: Monetizing social media. Digital Inelligence Today. [Online]. Available: https://digitalintelligencetoday.com/documents/Syzygy 2010.pdf

[74] D. McKnight and N. Chervany. (2001, December) Trust and distrust definitions: One bite at a time. Springer Link. [Online]. Available: https://link.springer.com/chapter/10.1007/3-540-45547-7 3

[75] D. McKnight, V. Choudhury and C. Kacmar, Developing and validating trust measures for e-commerce: An integrative typology, Information Systems Research, vol. 13, no. 3, pp. 334-359, 2002.

[76] A. Mesquita, User Perception and Influencing Factors of Technology in Everyday Life. Hershey, USA: IGI Global, 2013.

[77] A. Mohmed, N. Azizan and M. Jali, The impact of trust and past experience on intention to purchase in ecommerce, International Journal of Engineering Research and development. vol. 7, no.10, pp. 28-35, 2013.

[78] S. Molinillo, F. Liébana-Cabanillas and R. Anaya-Sánchez, A Social Commerce intention model for traditional ecommerce sites, Journal of Theoretical and Applied Electronic Commerce Research, vol. 13, no. 2, pp. 80-93, 2018.

[79] R. Naylor, C. Lamberton and P. West, Beyond the Like Button: The Impact of Mere Virtual Presence on Brand Evaluations and Purchase Intentions in Social Media Settings, Journal of Marketing, vol. 76, no. 6, pp. 105-120, 2012.

[80] C. Ng, Intention to purchase on social commerce websites across cultures: A cross-regional study, Information \& Management, vol. 50, no. 8, pp. 609-620, 2013.

[81] C. Ou, P. Pavlou and R. Davison, Swift guanxi in online marketplaces: The role of computer-mediated communication technologies, MIS Quarterly, vol. 38, no.1, pp. 209-230, 2014.

[82] J. Park and L. Stoel, Effect of brand familiarity, experience and information on online apparel purchase, International Journal of Retail \& Distribution Management, vol. 33, no. 2, pp. 148-160, 2005.

[83] E. Park, SNS Users' Trust impact on purchase intentions of fashion products, presented at the Global Fashion Management Conference, Vienna, July 6-9, 2017.

[84] P. Pavlou and A. Dimoka, The nature and role of feedback text comments in online marketplaces: Implications for trust building, price premiums, and seller differentiation, Information Systems Research, vol. 17, no. 4, pp. $392-414,2006$. 
[85] F. Piller and D. Walcher, Toolkits for idea competitions: A novel method to integrate users in new product development, R\&D Management, vol. 36, no. 3, pp. 307-318, 2006.

[86] W. Reinartz, M. Haenlein and J. Henseler, An empirical comparison of the efficacy of covariance-based and variance-based SEM, International Journal of Market Research, vol. 26, no. 4, pp. 332-344, 2009.

[87] N. Richter, R. Sinkovics, C. Ringle, and C. Schlaegel, A critical look at the use of SEM in international business research, International Marketing Review, vol. 33, no. 3, pp. 376-404, 2016.

[88] M. Salehan, S. Kashipaz and C. Xu. (2013, May) Information sharing on social networking websites: Antecedents and consequences of trust. AIS Electronic Library (AISeL). [Online]. Available: https://aisel.aisnet.org/amcis2013/SocialTechnicallssues/GeneralPresentations/15/

[89] M. Senecal and J. Nantel, The influence of online product recommendations on consumers' online choices, Journal of Retailing, vol. 80, no. 2, pp. 159-169, 2004.

[90] S. Sharma, P. Menard and L. Mutchler, Who to Trust? Applying trust to social commerce, Journal of Computer Information Systems, vol. 56, no. 2, pp. 1-11, 2017.

[91] J. Shen, Social comparison, social presence, and enjoyment in the acceptance of social shopping websites, Journal of Electronic Commerce Research, vol. 13, no. 3, pp. 198-212, 2012.

[92] D. Shin, The effects of trust, security and privacy in social networking: A security-based approach to understand the pattern of adoption, Interacting with Computers, vol. 22, no. 5, pp. 428-438, 2010.

[93] D. Shin, User experience in social commerce: in friends we trust', Behaviour and Information Technology, vol. 32 , no. 1, pp. 52-67, 2013.

[94] J. Short, E. Williams and B. Christie, The Social Psychology of Telecommunications. London: John Wiley, 1976.

[95] M. Sobel, Asymptotic confidence intervals for indirect effects in structural equation models, Sociological Methodology, vol. 13, no. 1, pp. 290-312, 1982.

[96] B. Suh and I. Han, The impact of customer trust and perception of security control on the acceptance of electronic commerce, International Journal of electronic commerce, vol. 7, no. 3, pp. 135-161, 2003.

[97] T. Tanadi, B. Samadi and B. Gharleghi, The impact of perceived risks and perceived benefits to improve an online intention among generation-Y in Malaysia, Asian Social Science, vol. 11, no. 26, pp. 226-238, 2015.

[98] Technavio. (2017, July) Global social commerce market 2017-2021. Technavio. [Online]. Available: https://www.technavio.com/report/global-social-commerce-market

[99] T. Teo and Y. Yeong, Assessing the consumer decision process in the digital marketplace, The International Journal of Management Science, vol. 31, no. 1, pp. 349-363, 2003.

[100]B. Van Der Heide and Y. Lim, On the conditional cueing of credibility heuristics: The case of online influence, Communication Research, vol. 3, no. 4, pp. 1-22, 2015.

[101]W. Wandoko, B. Abbas, D. Budiastuti, and R. Kosala, Online trust building through third party trust transfer and third party protection, Journal of Physics: Conference Series, vol. 801, no. 1, pp. 1-8, 2017.

[102] C. Wang and P. Zhang, The evolution of social commerce: The people, management, technology, and information dimensions, Communications of the Association for Information Systems, vol. 31, no. 5, pp. 105127, 2012.

[103]Y. Wang, Antecedents of social network trust in SNS usage: The moderating role of offline familiarity, Social Networking, vol. 6, no. 2, pp. 107-134, 2017.

[104] W. Wang, X. Cui, L. Huang, and Y. Dai, Seller reputation or product presentation? An empirical investigation from cue utilization perspective, International Journal of Information Management, vol. 36, no. 3, pp. 271-283, 2016.

[105]W. Wu, T. Chan and H. Lau, Does consumers' personal reciprocity affect future purchase intentions?, Journal of Marketing Management, vol. 24, no. 3-4, pp. 345-360, 2008

[106] M. Yadav, K. De Valck, T. Hennig-Thurau, D. Hoffman, and M. Spann, Social commerce: A contingency framework for assessing marketing potential, Journal of Interactive Marketing, vol. 27, no. 4, pp. 311-323, 2013.

[107] H. Yaseen, M. Alhusban, K. Dingley, and A. Alhosban, Facilitating e-commerce in Jordan: A qualitative analysis, International Journal of Digital Society (IJDS), vol. 7, no. 4, pp.1206-1213, 2016.

[108] T. Yigitcanlar, Rethinking Sustainable Development: Urban Management, Engineering, and Design. USA: Idea Group Inc (IGI), 2010.

[109]A. York, (2017, March) Social media demographics to inform a better segmentation strategy. Sprout Social. [Online]. Available: https://sproutsocial.com/insights/new-social-media-demographics/

[110]Z. Yun, Testing a theoretical model to examine the relationships among e-social shopping motivation, perception, and behavioral intention, Ph.D. dissertation, Department of Retailing, Michigan State University, Michigan, 2011.

[111]K. Zhang and M. Benyoucef, Consumer behavior in social commerce: A literature review, Decision Support Systems, vol. 86, no. 1, pp. 95-108, 2016.

[112]D. Zhu and Y. Chang, Effects of interactions and product information on initial purchase intention in product placement in social games: The moderating role of product familiarity, Journal of Electronic Commerce Research, vol. 16, no. 1, pp. 22-33, 2015. 